resumed. Eventually Dempsey "won” the contest and retained the heavyweight title.

This is, of course, not the only time that cheating has paid in sport. I wonder how many who view the picture in the Whitney Museum are aware of its irony.

Richmond,

Surrev TW' $1 \mathrm{XZ}$

1 Corsellis JAN. Boxing and the brain. Br.Hed f 1989:298:105-9. (1+ January.

\section{Are all infants of diabetic mothers "macrosomic"?}

SIR,-While applauding $\operatorname{Dr} \mathrm{R} \mathrm{J}$ Bradley and colleagues for trying to break away from the simplistic concept of diabetic mothers being either macrosomic or not,' I do have some reservations about their data.

They included a few women with gestational diabetes, who themselves form a heterogenous group. They did not need to swell their numbers in this way, and thus open themselves to criticism, since they had enough women with insulin dependent diabetes in their study. A more important reservation concerns their choice of controls. They seem to have contrasted their diabetics with the total population of women delivering in their district. I run a similar clinic and would find this comparison invalid for my population. I suspect it is for theirs as well for two main reasons.

Firstly, their diabetic women will be mainly from outside their district and are probably of a higher social class than their indigenous hospital population and so one would expect them to have heavier babies. Secondly, their hospital population probably contains a higher proportion of nonwhite mothers than their diabetic population, which again would make the diabetic women seem to have heavier babies for reasons unrelated to their diabetes.

Finally, I was surprised not to see a small increase in low birthweight babies among mothers with diabetic vascular disease (White's class $F, R$ ), a finding in my own clinic.

MICHAEL MARESH

St Mary's Hospital,

Manchester $\mathrm{M} 130 \mathrm{JH}$

1 Bradler RJ, Nicolaides KH, Brudenell JM. Are all infants of diabetic mothers "macrosomic"? Br Med f 1988:297:1583-4. 17 December.

AUTHORS' REPLY, - The birth weights (expressed as the difference in standard deviations from the mean for gestation) of the infants of women with gestational diabetes (mean +0.95 ; SD $1 \cdot 28$ ) did not differ significantly from those of the infants of insulin dependent mothers (mean $+1 \cdot 27$; SD $1 \cdot 36$ ), and in both groups the birth weights were significantly greater $(p<0.0001)$ than our reference range (figure).

It is true that birth weight is influenced by social class and race. The social class of our diabetic patients did not, however, differ from that of the non-diabetics. Although about $30 \%$ of our pregnant diabetic patients are referred from outside our district, the mechanism of referral, by consultant physicians, is not influenced by social class. As for race, $42 \%$ of the pregnant women delivering at King's College Hospital are nonwhite, but $67 \%$ of these women are of AfroCaribbean origin and have a similar birthweigh distribution to that of the white population. In parts of Britain such as Manchester the predominance of women of Asian origin, who are known to have smaller babies, may indeed lower the mean birth weight of the reference range

Diabetic nephropathy and severe vascular

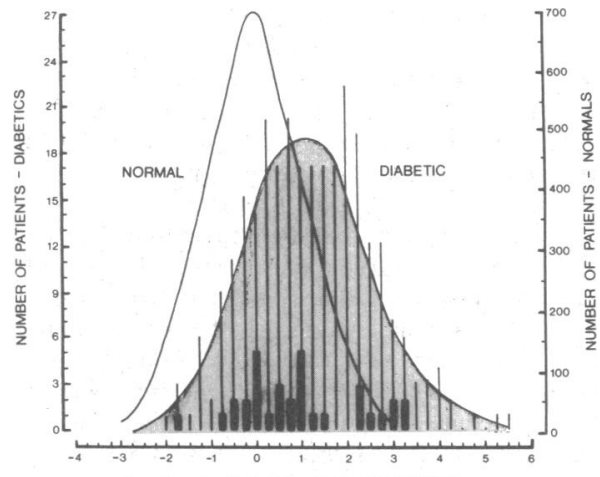

BIRTHWEIGHT (STANDARD DEVIATIONS)

Distribution of birth weights (standard deviations from the mean for gestational age) for 280 infants of diabetics (gestational diabetics shown by heavy bars) and 3959 infants of normal mother

disease are associated with lower birth weights but their contribution is small as they affect less than $10 \%$ of our pregnant diabetics. In these cases the infants may in fact be growth retarded by the effects of the vasculopathy but the growth promoting effect of maternal diabetes will to some extent counterbalance this and produce a baby with a birth weight below the normal range fo diabetics but within that for non-diabetics.

R J BRADLEY K H NICOLAIDFS J M BRUDENELI

Harris Birthright Research Centre for Fetal Medicine.

King's College School of Medicine and Dentistry.

London SE5 8RX

SIR, - Dr R J Bradley and colleagues draw attention to misuse of the word "macrosomic" a applied to the infants of mothers with diabetes mellitus but by discussing only their data on birth weight have missed the opportunity to clarify the position.'

Macrosomia correctly describes the pathological excessive enlargement of fetal tissues dependent on fetal insulin levels for growth. This must be only crudely reflected by birth weight because some organs - for example, the brain ${ }^{2}$ and thymus ${ }^{3}-$ are less heavy than in infants of non-diabetic women. Moreover, diabetic women with vascular complications in White's class $\mathrm{F}^{+}$(as modified by Pedersen - that is, nephropathy or proliferative retinopathy, or both $^{5}$ ) have growth retarded babies.

The extent to which glycaemic regulation affects birth weight for gestational age in women with insulin dependent diabetes mellitus is controversial, but it may be related to a lack of detailed knowledge of glucose homoeostasis throughou pregnancy so that notional therapeutic targets could be ill founded and erroneous. Hypertrophy of the fetal islets may occur as early as the fourth month of pregnancy, ${ }^{6}$ suggesting that these may respond to the effects of suboptimal materna metabolic regulation before this time. When at first the change was made in Aberdeen from reverse testing urinary glucose to home blood glucose monitoring as the indicator for adjustment of maternal insulin dose before and during pregnancy the birth weights of successive babies in the same women were reduced below the 50 th centile with no change in the White's class in five out of six cases.' The reduction was against the parity effect of increasing birth weight for gestation, and the

women did not qualify for change in their White's classification by the time of the later delivery. This was interpreted as support for the findings of Molsted-Pedersen, who showed that the regression lines between newborn $\mathrm{k}$ values and birth weigh gave a graphic representation of a growth impulse through the glucose-insulin system." A proportion of pregnant women with insulin dependen diabetes mellitus experience difficulty in regulat ing their diabetes for various reasons or are poorly compliant, and in such cases fetal $\beta$ cell macropolynesia with resulting hyperinsulinism and classical macrosomia is to be expected. Taken together these observations would lead to a suspicion that there is a w shaped distribution of birth weight in infants of diabetic mothers if these mothers have been attempting to achieve optimal metabolic control throughout pregnancy.

Examination of the obstetric records of mothers with insulin dependent diabetes living in Grampian, Orkney, and Shetland between 1977 and 1987 inclusive does not confirm the finding of Dr. Bradley and his colleagues that babies of diabetic women show a unimodal normal distribution of birth weight for gestation uniformly shifted towards higher birth weight for gestation than in the population in which the diabetic pregnancies occurred.

During the 11 year study in Grampian there were 195 pregnancies in the diabetic women. Eighty three women had one birth weight included, 25 women had two, and eight women had three. The protocol for management of these pregnancies has been published." Thirty four women $(16 \%)$ aborted; five women were excluded from the analysis-two sets of twins and three whose records are no longer available in Grampianleaving 157 liveborn singleton pregnancies for which accurate birthweight centiles could be ascribed. The centile calculations are based on data of over 50000 birth weights for women in the same area. ${ }^{10}$ The allocation of the birthweight centile takes into account the sex and gestational age of the baby and the height, weight for height, parity, and social class of the mother in each case (table). The White's class distribution was: B, 71 (45\%); C, 48 $(31 \%) ; \mathrm{D}, 22(14 \%)$; and $\mathrm{F}$ and $\mathrm{R}, 16(10 \%)$

Nearly half $(48 \%)$ of the group with diabetes was distributed below the 50th centile. For this group, ranking the representation of birth weights in quartiles from high to low produces the sequence $\geqslant 75$ and $<25,25-<50$, and $50-<75$. The overall distribution is significantly different from the population distribution with an excess at both ends - that is, below the 5th and at or above the 95 th centiles - that at or above the 95 th centile being significant.

Without more information about Dr Bradley and others' patients it is difficult to determine why the results are so different. The London control group $(n=3959)$ were hospital births and not geographically based. Such a sample is influenced therefore by catchment characteristics such as referral practice; King's College Hospital is known, for instance, to attract obstetric problems quite apart from diabetic pregnancies. Also, fewer than 4000 is a small sample on which to derive birthweight standards, particularly at early gestational ages. No detail is given of gestational ages at delivery in either the diabetic or control group. Were other factors known to affect birth weight - for example, antepartum stillbirth, fetal sex, and maternal smoking habit-disregarded? Presumably a much smaller proportion of the diabetic group were smokers.

Birthweight centile distribution for 157 women with insulin dependent diabetes, Grampian region, 1977-87

\begin{tabular}{lcccccccc}
\hline & $<5$ & $5-<10$ & $10-<25$ & $25-<50$ & $50-<75$ & $75-<90$ & $90-<95$ & $\geqslant 95$ \\
\hline No & 14 & 6 & 21 & 35 & 27 & 28 & 7 & 19 \\
Percentage & $8 \cdot 9$ & $3 \cdot 8$ & $13 \cdot 4$ & $22 \cdot 3$ & $17 \cdot 2$ & $17 \cdot 8$ & $4 \cdot 5$ & $12 \cdot 1$ \\
\hline
\end{tabular}

$\chi^{\prime}=16.93, p<0.025$ 
In our view Dr Bradley and his colleagues have failed to produce sufficiently secure evidence to allow them to conclude that in all infants of diabetic mothers growth is promoted to such a degree that "they should be considered to be at risk of the biochemical and mechanical consequences of macrosomia," and we express our concern that this conclusion may lead to an unnecessary and undesirable increase in the already high rate of caesarean sections in diabetic women.

HAMISH SUTHERLAND DORIS M CAMPBELL DONALD W M PEARSON

Combined Diabetic Antenatal Clinic,

Aberdeen Maternity Hospital,

Aberdeen AB9 2ZA

I Bradley RJ, Nicolaides RH, Brudenell JM. Are all infants of diabetic mothers "macrosomic"? Br Med f 1988;297: 1583-4. (17 December.)

2 Cardell BS. The infants of diabetic mothers: a morphologica study. Journal of Obstetrics and Gynaecology of the British Commonwealth 1953;60:834-53.

3 Gruenwald P. Growth of the human fetus. Abnormal growth in wins and infants of mothers with diabetes, hypertension or isoimmunization. Am J Obstet Gynecol 1966;94:1120-32.

4 White P. Pregnancy and diabetes-medical aspects. Med Clin North Am 1965;49:1015-24

5 Pedersen J. The pregnant diabetic and her newborm. 2nd ed. Munksgaard: Copenhagen, 1977:199.

6 Geyer A, Staeffen J. Cytologie du pancréas endocrine de deux foetus jumeau de quatre mois, sissus de mère diabetique. Presse Med 1957;65:1079.

7 Sutherland HW, Pedersen JF, Molsted-Pedersen L. Treatmen of diabetic pregnancy with special reference to fetal growth In: Van Assche FA, Robertson W'B, eds. Fetal growith In:
retardation. Edinburgh: Churchill Livingstone, 1981: retardation.

8 Molsted-Pedersen L. Aspects of carbohydrate metabolism in newborn infants of diaberic mothers. I Acta Endocrinol newborn infants of diabet
(Copenh) 1972;69:174-88

9 Sutherland HW, Pearson DWM, Powrie JK. Management of the pregnant diabetic patient. Drugs 1988;36:239-48.

10 Thomson AM, Billewicz WZ, Hytten FE. The assessment of fetal growth. Brf Obstet Gynecol 1968;75:903-16.

\section{Income and standards of living of disabled people}

SIR, - The Office of Population Censuses and Surveys' reports on disability, ${ }^{12}$ reviewed by Miss Daphne Gloag, ${ }^{3}$ have highlighted many problems of disabled people. The reports are, however, difficult to compare with others as the threshold of disability is much lower than was considered previously and the scoring system is not easily compared with existing measures of disability. This distortion complicates the discussion of the extra daily living costs incurred owing to disability.

We interviewed in their homes people aged 16 . 64 who were on the social services register of handicap in our area. ${ }^{+}$Our findings suggested that the costs quoted underestimate the true increased cost of disability. The mean personal extra costs for the 62 severely handicapped people (mean Barthel score 44 (SD 28)) was $£ 11$ (SD 20) at 1988 values, the standard deviation suggesting wide variation among the subjects. These costs increased to $£ 32$ (35) when the person had no informal carer. They did not include extra heating costs or loss of income to carers. Only two people had a regular earned income. Although major expenditure was incurred in employing people to help with physical care or with the home, the other main costs were in maintaining an electric wheelchair, replacing clothes and shoes, and the need for continence aids.

In a study of 111 appreciably handicapped people (mean Barthel score 76 (18)) on the same register' our impression has been that since the changes in social security in April 1988 no one has gained under the new system and many have received reduced benefit. None had used either the independent living fund or the social fund. Disabled people are unaware of value added tax exemption for many goods bought for reasons of disability and cannot take advantage of the discounts for bulk buying obtained by social services and health authorities. This has become more important with tighter local budgets Further, inflation for disabled people may be higher than that for the general population. ${ }^{\circ}$ Thus special regular needs and equipment may be more expensive.

Finally, we draw attention to the concept of satisfaction with present standards of living and services provided. This includes knowledge of what is available in terms of services, aids, and adaptations (statutory, voluntary, and private). If disabled people or their families have no knowledge of what is available they canno comment on its usefulness; dissemination of information is therefore important.

RICHARD G HULI ANDREW FRANK

Department of Rehabilitation

Northwick Park Hospital

Harrow,

Middlesex HAl 3U

Basingstoke District Hospital

Basingstoke,

Hampshire

1 Martin J, Meltzer H, Elliot D. Office of Population Censuses and Surveys, survey of disability in Great Brtuin, report 1: the prevalence of disability among adults. London: HMSO, 1988

2 Martin J, White A. Office of Population Censuses and Survey, survey of disability in Great Britain, report 2: the financial circumstances of disabled adults living in private households. London: HMSO, 1988.

3 Gloag D. Income and standards of living of disabled people. Br Med F 1988:297:1428. (3 December.)

4 Prouse PJ, Brill M, Towsend J, Ross-Smith K, Frank AO. Costs of community care for younger disabled people. Int $\mathcal{F}$ Rehabil Res 1987:10.399.

5 Hull RG, Prouse PJ, Sherrat C, Brennan P, Frank AO. Medica diagnosis and level of disability in appreciably handicapped people at home. Int $\mathcal{F}$ Rehabil Res (in press).

6 Hammerman S, Maikowski S. The economics of disabilitie international perspectives. Int $\mathcal{F}$ Rehabil Res 1982;5:149-66.

7 Royal College of Physicians. Physical disability in 1986 and beyond. I R Coll Physicians Lond 1986;20:3-37.

8 Feidler B. Living options lottery: housing and support services for people with severe physical disabilities 1986/88. London: Prince of Wales's Advisory Group on Disability, 1988.

\section{Vindaloo and you}

SIR, - Dr Ingvar Bjarnason and colleagues do not suggest possible mechanisms for changes in permeability after eating vindaloo dishes. ' There is some biochemical reasoning behind the study of permeability after curries. Capsaicin is the main irritant ingredient of cayenne pepper and capsicums. Capsaicin releases substance $\mathbf{P}$ from nerve endings, ${ }^{2}$ and this undecapeptide has profound effects on contractility of smooth muscle. This in itself might be responsible for the irritable bowel-like effects of curries. In addition, substance $P$ causes mast cell degranulation in vitro, ${ }^{4}$ and we have shown that anaphylaxis and mast cell degranulation in animals cause a transient increase in permeability which returns to normal within a few hours afterwards.

We performed a similar experiment in 1986 with the idea of offering a paper for the Christmas edition of the $B M \mathcal{F}$ but did not submit it in view of negative results. Eight healthy volunteers had permeability tests before and after a hot Indian meal. Each volunteer swallowed edetic acid labelled with $9 \cdot 3 \mathrm{MBq}$ chromium-51 at 0800 (having fasted overnight ) on two separate occasions once two days before and once the morning after the Indian meal. Urine was collected for 24 hours and the amounts of radiolabelled edetic acid determined and compared with standards as previously described. Mean 24 hour urinary excretion, expressed as a percentage of the dose, was 1.43 before the meal and 1.52 after the meal (mean difference $0.09,95 \%$ confidence interval -0.48 to $0 \cdot 29$ ).

We found no change in permeability due to eating spicy foods, which supports the findings of Dr Bjarnason and colleagues. In their study recovery of radiolabelled edetic acid in the urine seemed to be slightly increased, although the lower $95 \%$ confidence limit was close to zero at $0 \cdot 02$. In addition, taking only a five hour urine sample may increase any errors due to changes in intestinal transit, although the authors have previously stated that in animal models a change in gut transit does not affect the permeability to this probe.

Both our studies and those of Dr Bjarnason and others may have measured permeability too late after ingestion. Further studies with a hotter curry and the urine sample taken immediately after the meal would be interesting. It would be paradoxical if the simple curry were to throw light, or indeed heat, on the expanding academic subject of gastrointestinal neuroimmunology.

JOHN K RAMAGE

Department of Gastroenterology

Royal Naval Hospital,

Haslar (iosport,

Hampshire PO12 2Ad

Division of Gastroenterolog:

RICHARD H HUNT

Mivision of Gastroenterology,

Hamilton,

Ontario, Canada

Bjarnason I, Levi S, Smethurst P, Menzies IS, Levi AJ. Vindaloo and you. Br.Med F 1988;297: 1629-31. (24-31 December.)

2 Gamse $R$, Holzer $P$, Lembeck $F$. Decrease of substance $P$ in primary afferent neurone and impairment of neurogenic plasma extravasation by capsaicin. Br f Pharmacol 1980;68 207-13.

3 Leander S, Hakanson R, Rosell S, Folkers K, Sundler F, Tornqvist $K$. Specific substance $P$ antagonist blocks smooth muscle contractions induced by non-cholinergic nonadrenergic nerve stimulation. Nature 1981;294:467-9.

Shanahan F, Denburg JA, Fox J, Bienenstock J, Befus D. Mast cell heterogeneity: effects of neuroenteric peptides on histamine release. F Immunol 1985; 135:1331-7.

Ramage JK, Stanisz A, Scicchitano R, Hunt RH, Perdue $M H$. Cortan of increal red permeability to Correlain of increased perseability 10 Cr-EDTA and (iastroenterology 1988.94:1368:75.

6 Bjarnason I, Smethurst P, Levi AJ, Peters TJ. Intestinal permeability to "Cr-EDTA in rats with experimentally permeability to "Cr-EDTA in rats with

7 Bienenstock J, Perdue M, Stanisz A, Stead R. Neurohumoral regulation of gstrointestinal immunity. Gastroenterolog 1987;93:1+31-4.

SIR, - I read the paper by Dr Ingvar Bjarnason and others with scientific interest and gastronomic admiration.' $\mathrm{My}$ experience of eating Indian food - at least as a medical student - is that curries are often washed down with volumes of beer or lager. In view of previous work in rats showing that ethanol promotes the absorption of smal molecules into and through the mucosa of the smal intestine $e^{2}$ (in that case horseradish peroxidase), I wonder whether the results from Harrow can be explained on the basis of ethanol rather than spices.

Department of Respiratory Medicine,

JON G AYRES

East Birmingham Hospital,

Birmingham B9 5ST

Bjarnason I, Levi S, Smethurst P, Menzies IS, Levi AJ. Vindalo and you. Br.Med F 1988;297:1629-31. (24-31 December.)

2 Draper LR, Gyure LA, Hall JG, Robertson D. The effect of alcohol on the integrity of the intestinal epithelium. $G u$ 1983;24:399-40.

Authors' REPLY, - In the interests of science (as stated in our introduction) and the known effects of even British beer on the small intestine' the volunteers deprived themselves of any curry lubricant throughout the study.

INGVAR BJARNASON PAUL SMETHURST SASSOON LEVI IAN S MENZIES A JONATHAN LEVI

Clinical Research Centre,

Harrow HA1 3UJ

I Bjarnason I, Ward K, Peters TJ. The leaky gut of alcoholism. Lancet $1984 ; \mathrm{i}: 179-82$ 